\title{
Are social conflicts at work associated with depressive symptomatology? Results from the population-based LIFE-Adult-Study
}

\author{
Andrea E. Zuelke ${ }^{1 *}$ D, Susanne Roehr ${ }^{1}$, Matthias L. Schroeter ${ }^{2,3}$, A. Veronica Witte ${ }^{2}$, Andreas Hinz ${ }^{4}$, Christoph Engel ${ }^{5}$, \\ Cornelia Enzenbach ${ }^{5}$, Joachim Thiery ${ }^{6}$, Markus Loeffler ${ }^{5}$, Arno Villringer ${ }^{2,3}$ and Steffi G. Riedel-Heller ${ }^{1}$
}

\begin{abstract}
Background: Psychosocial stressors in the workplace can be detrimental to mental health. Conflicts at work, e.g. aggression, hostility or threats from coworkers, supervisors or customers, can be considered a psychosocial stressor, possibly increasing risk for depressive symptoms. Existing studies, however, differ in the assessment of social conflicts, i.e. as individual- or job-level characteristics. Here, we investigated the association between conflicts at work assessed as objective job characteristics, and depressive symptomatology, using data from a large population-based sample. Additionally, we investigated gender differences and the impact of personality traits and social resources.

Methods: We used data from the population-based LIFE-Adult-Study from Leipzig, Germany. Information on conflicts at work, assessed as job characteristics, were drawn from the Occupational Information Network, depressive symptoms were assessed via the Center for Epidemiological Studies Depression Scale. Multilevel linear regression models with individuals and occupations as levels of analysis were applied to investigate the association between conflicts at work and depressive symptoms.
\end{abstract}

Results: Our sample included 2164 employed adults (age: 18-65 years, mean: 49.3, SD: 7.9) in 65 occupations. No association between conflicts $s$ at work and depressive symptomatology was found (men: $b=-0.14 ; p=0.74$, women: $b=0.17, p=0.72$ ). Risk for depression was mostly explained by individual-level factors like e.g. neuroticism or level of social resources. The model showed slightly higher explanatory power in the female subsample.

Conclusion: Conflicts at work, assessed as objective job characteristics, were not associated with depressive symptoms. Possible links between interpersonal conflict and impaired mental health might rather be explained by subjective perceptions of social stressors and individual coping styles.

Keywords: CES-D, Depressive symptoms, Mental health, Psychosocial work environment, Social conflict, Multilevel model, O*NET

\section{Background}

The working environment and job characteristics have a crucial influence on well-being and mental health, which in turn impact work performance and productivity [1-3]. Given the average duration of working life in the European Union currently amounts to 36.2 years, meaning that people spend more than one third of their lives in

\footnotetext{
* Correspondence: Andrea.Zuelke@medizin.uni-leipzig.de

${ }^{1}$ Institute of Social Medicine, Occupational Health and Public Health (ISAP), Medical Faculty, University of Leipzig, Philipp-Rosenthal-Str. 55, 04103 Leipzig, Germany

Full list of author information is available at the end of the article
}

employment, it can be assumed that many sources of perceived stress are encountered in the workplace $[4,5]$. Therefore, understanding how the social environment at work can enhance or impair mental health is crucial. Occupational health research in the last decades has particularly focused on the dimensions of work demands and control, drawing on Karasek and Theorell's demandcontrol-model [2, 6-8]. Later amendments have added another dimension - social support -, leading to the demand-control-support-model $[9,10]$. It is assumed that impaired mental health and well-being can be found especially in people holding jobs characterized by high strain

(c) The Author(s). 2020 Open Access This article is distributed under the terms of the Creative Commons Attribution 4.0 International License (http://creativecommons.org/licenses/by/4.0/), which permits unrestricted use, distribution, and reproduction in any medium, provided you give appropriate credit to the original author(s) and the source, provide a link to the Creative Commons license, and indicate if changes were made. The Creative Commons Public Domain Dedication waiver (http://creativecommons.org/publicdomain/zero/1.0/) applies to the data made available in this article, unless otherwise stated. 
(high demands but low control) and low social support. Recent meta-analyses found higher risks for clinical depression $[2,7,11]$ and depressive symptoms $[6]$ in people experiencing job strain, reporting mostly small to medium effect sizes.

While the demand-control-(support) model provides a highly valuable measure for important aspects of work organization, it has been argued that other psychosocial aspects of the working environment are still understudied $[6,12-15]$. This also applies to social conflicts at work and their possible association with mental health $[16,17]$. The World Health Organization emphasizes the meaning of interpersonal relations at work for (mental) health, stressing that poor relations and conflicts with co-workers or supervisors can increase risk for mental illness [18]. Interestingly, the original article introducing the demand-control-model explicitly named social conflicts at work as a stressor, stating that job demands include "psychological stressors involved in accomplishing the workload, stressors relating to unexpected tasks, and stressors of job-related personal conflict" [8]. Against this background, social conflicts can be considered a stressful work demand, increasing risk of depression.

Social conflicts in the workplace can broadly be defined as a range of interpersonal maltreatment behaviors. It can include e.g. rude behavior, verbal aggression, bullying or physical assault $[16,19]$ and can result in negative consequences such as increased rates of turnover, less productivity and employee satisfaction [20, 21]. The literature supports a link between higher rates of interpersonal conflict at work and depression, whereas interpersonal conflict acts as a major stressor. Most investigations of social conflicts at work focus on occupations in the service sector, e.g. cashiers, call-center agents or bus drivers, since these jobs entail a high level of interpersonal contacts with colleagues and customers [22]. Somewhat paradoxically, the literature also reports a high prevalence of social conflict in professions with a strong focus on caring like nursing [23, 24] or teaching $[25,26]$. Several studies in different work settings reported social conflict at work the single most important source of perceived stress $[17,27,28]$.

A common criticism concerning studies on occupational mental health refers to the fact that most empirical studies rely on self-reported measures both of independent and outcome variables [6, 29-34]. Therefore, individuals in identical jobs can rate the amount of job stress or, specifically, work-related conflict quite differently. This might especially be true for people experiencing depressive symptoms, which may influence their affective assessment of their job and working environment [32]. Furthermore, only few validated instruments measuring subjective job-related stressors are available. To account for this risk of bias, a growing body of research investigates associations between psychosocial factors of working environments and mental health by drawing on objective assessments of occupational information, e.g. [30, 35-37]. Rather than broad categories like "perceived stress", these assessments could possibly provide a clearer indication of the actual environmental conditions that are linked to depression and, therefore, knowledge on what aspects of the working environment need changing, allowing for effective prevention strategies [38, 39]. Lastly, previous studies on occupational mental health have often focused on jobs in the service sector, using rather small and very specific samples. More comprehensive investigations using populationbased samples are currently rare, especially in Germany.

Another point of discussion refers to the level and unit of analysis: It can be argued that occupational stressors refer to qualities of jobs rather than of individual people [29, 40-42]. Despite this, most empirical investigations so far have relied solely on individual-level data. That said, workers holding the same job, i.e. individuals nested within jobs, cannot reasonably be regarded as independent units of analysis, which in turn violates important assumptions of standard ordinary least squares (OLS) regression techniques [29]. Ignoring the potential effect of clustering bears the risk of overestimating the importance of regression coefficients [40]. Therefore, it has been argued that the hierarchical structure of workers in jobs shall be recognized by choosing appropriate techniques of analysis like e.g. multilevel modeling $[41,42]$.

Several factors have been identified to moderate the link between psychosocial work characteristics and depressive symptoms. Neuroticism and extraversion have been found to be linked to depressive symptoms: There is a strong correlation between neuroticism and increased risk of depression, while high levels of extraversion act as a protective factor against depressive symptomatology [43-46]. It has been shown empirically that the negative effect of neuroticism is especially pronounced under stressful conditions, i.e. adversity and conflictual situations are especially harmful for people showing high degrees of neuroticism [47]. Social support from friends or family has been found a protective factor against depression in several studies (for an overview, see [48]). Protective effects against depression have also been found for higher levels of education $[49,50]$.

The role of gender in the relationship between workrelated psychosocial stressors and mental health is still inconclusive. While some researchers report stronger effects of occupational stressors on men's health [51], others found the relationship to be stronger in women $[52,53]$ or reported no gender differences [6]. Possible gender differences in the association of work-related stressors with depressive symptoms might occur for 
different reasons: First, women and men can differ in the degree of exposure to occupational stressors, namely: interpersonal conflict. While most studies reported men and women to be equally affected by conflicts in the workplace, others found higher rates of exposure among women (for an overview, see [54]). More detailed investigations revealed that men mostly reported conflicts with male supervisors, whereas women experience conflicts both with men and women alike and with both supervisors and colleagues in equal proportions [54]. Women, however, are more likely to perceive conflictual situations as sexual harassment [55], which might possibly overlap with social conflicts. Second, men and women might differ in their coping strategies, i.e. ways of handling interpersonal conflict, or in their resources available for handling stressors at work. It has been shown that, due to gendered socialization processes, men tend to cope with stress more instrumentally, while women are more likely to openly express emotions $[17,56]$. Studies on (occupational) stress have found men to use more problem-oriented strategies whereas women are, on average, more emotion-focused [17].

Against this background, this study seeks to investigate the association between conflict at work and depressive symptoms, using a large population-based sample comprising a variety of different occupations. We hypothesize that a) higher levels of conflict at work are associated with increased depressive symptoms, b) the association will be smaller than in studies using self-report measures of interpersonal conflict. This is due to the objective assessment of interpersonal conflict as a feature of occupations in our study which does not capture different individual perceptions of stressors between workers holding the same job. We further investigate the influence of c) personality traits, i.e. neuroticism and extraversion, as well as social resources and education on the association. Neuroticism is assumed to be linked to increased levels of depression, whereas extraversion, higher levels of social resources and education should be associated with decreased depressive symptoms. Lastly, we seek to investigate possible gender differences.

\section{Subjects and methods Participants}

We used data from the LIFE-Adult-Study, a populationbased cohort study conducted by the Leipzig Research Center for Civilization Diseases. 10,000 randomly selected inhabitants of Leipzig, Germany (aged between 18 and 79 years) completed the baseline-examination between 2011 and 2014. The LIFE-Study aims to investigate the prevalence, genetic predispositions and modifiable lifestyle factors of major civilization diseases such as cardiovascular diseases, dementia or depression. Physical examinations, structured interviews and questionnaires were administered to all participants as part of the baseline assessment. Pregnancy and insufficient command of the German language were exclusion criteria. For a detailed description of the study aims and concept, see [57]. The study included an age- and sex-stratified random sample of 10,000 community-dwelling German-speaking residents of the city of Leipzig who were randomly drawn from lists provided by the local registry office. These residents were sent an invitation letter, containing information on the aims and design of the study, and a response form. If residents did not respond, a reminder invitation was sent. Non-responders were searched in public phone directories and contacted by phone. For residents who refused to participate, residents of the same age and sex were randomly drawn from the registry office's lists and invited to participate.

Out of the initial study sample, we excluded cases aged 66 years and older ( $n=3249$ cases) in order to exclude individuals who had already retired. Additionally, individuals who were not working $(n=1446$ cases), working less than $15 \mathrm{~h}$ per week $(n=159)$ or had no information on current employment status $(n=10)$ were dropped from the analyses. We further excluded cases with missing values on CES-D score $(n=348)$, LSNS $(n=217)$, NEO-16 AM-info on neuroticism/extraversion $(n=318)$, education $(\mathrm{n}=1)$ and occupations that could not be clearly matched with an O*NET-occupation identifier $(n=42)$. To avoid bias caused by small groups, observations were dropped if the respective occupation had less than 10 incumbents in the dataset $(n=1096$ observations). Finally, we excluded cases with missing values on the conflict-variables ( $n=46$ cases) and the lowest quintiles for the variables "frequency of conflict situations" $(n=427)$, "dealing with unpleasant or angry people" $(n=$ $167)$, "dealing with physically aggressive people" $(n=$ 310). The final sample contained 2164 individuals.

\section{Measures \\ Depressive symptoms}

Depressive symptoms were assessed using the Center for Epidemiologic Studies Depression Scale (CES-D [58]). This self-report scale comprises 20 items, assessing depressive symptoms such as depressed mood, hopelessness or insecurity during the last week, using a 4-pointLikert-scale $(0=$ never/almost none of the time; $3=$ most or all of the time). The score ranges from 0 to 60 points, with higher values indicating higher levels of current depressive symptomatology. Drawing on reference values from comparable population-based samples, a cut-off value of $\geq 23$ points indicates risk of depression [59].

\section{Individual-level covariates}

We included gender and age as individual-level covariates in our analyses. To control for social resources, we 
used information from the short-form of the Lubben Social Network-Scale (LSNS-6), a measure assessing perceived social resources and support. Questions include e.g. "How many friends/relatives do you see or hear from at least once a month?" or "How many friends/relatives do you feel close to such as that you could call on them for help?". Possible scores range from 0 to 30 points, higher scores indicating higher levels of social resources. A score below 12 points is considered an indicator of social isolation [60]. We further controlled for neuroticism and extraversion as assessed by the NEO-16 Adjective Measure [61]. Neuroticism and extraversion were assessed with four and three items, respectively. Participants rated themselves on a 7-point scale ranging from 1 (disagree strongly) to 7 (agree strongly), with the common introduction "I see myself as: (e.g. item 5: anxious)". We classified education (low, middle, high) based on the CASMIN-scale (Comparative Analysis of Social Mobility in Industrialized Nations), which takes into account general and vocational education [62].

\section{Occupational-level covariates}

We used occupational information from the Occupational Information Network (O*NET) database (version 23.2). The O*NET-database was developed by the US Department of Labor/Employment and Training Administration (USDOL/ETA) and provides detailed information on a total of over 900 different occupations within the USAmerican labor-market [63]. Data are provided by job incumbents, supervisors and occupational experts. Comparable databases for the German labor market are currently not available. O*NET data have been used to measure associations of work-related factors with depressive symptoms [35], cardiovascular disease [30], clinical depression [36], self-rated health and hypertension [64], among others. For every type of occupation, a comprehensive set of descriptors is available, including information on required skills, knowledge, values and activities common in the respective occupation. Among the section on worker activities, items assessing the importance and level/frequency of several types of social interactions in the workplace are available. Interpersonal conflict is assessed with three items: frequency of conflict situation; dealing with unpleasant or angry people; dealing with physically aggressive people. The three items were combined into one additive "conflict-score" as an overallmeasure of interpersonal conflict in the workplace by summing up the values of the three respective items. Cronbach's alpha was 0.87 , indicating a high level of internal consistency.

Since some occupations experience literally no conflictual contacts, observations were grouped into quintiles based on their respective scores in the three conflict-items. The lowest quintile was then removed from the analysis sample. To avoid the risk of bias due to statistical outliers, we excluded occupations with less than 10 incumbents from the sample.

\section{Statistical analyses}

To describe the sample with regard to individual- and occupational-level characteristics, $\mathrm{Chi}^{2}$ - and two-sample t-tests were used as appropriate. We conducted an overall-analysis of the complete sample as well as separate analyses for men and women. Subsequently, we investigated associations between interpersonal conflict in the workplace and depressive symptomatology by calculating a linear multilevel regression model. Multilevel models are suited for analyzing hierarchically structured data, e.g. individuals (level 1-units) clustered in occupations (level 2 -units). $P$-values $<0.05$ were considered significant, and all models were calculated using maximum likelihood estimation. Analyses were conducted using Stata (SE) 13.1. We first fit an empty model (null model), containing only the random effects of individuals and occupations, to determine the proportion of differences in depressive symptoms due to different occupations. In a next step, all individual-level factors are added to the analysis, resulting in a random interceptmodel. The final model additionally contains individual and occupational-level covariates. As an indicator for model-fit, the Akaike information criterion (AIC) is reported for each model, with smaller values indicating better model-fit.

\section{Results}

Table 1 provides a description of independent and dependent variables. The final sample consisted of 856/ $39.6 \%$ men and $1308 / 60.4 \%$ women with a mean age of 49.4 (SD: 8.1) and 49.3 years (SD: 7.7) for men and women, respectively, (nested in 65 distinct occupations. Each occupation included, on average, 33 workers (minimum: 10, maximum: 252). Mean CES-D-scores were 8.6 (SD: 5.4) for men and 10.8 (SD: 7.6) for women, respectively (overall score: 10.0, SD: 6.9). Women in our sample had higher values in neuroticism (mean $=3.4$ vs. 3.0 in men, $P<0.001$ ) and extraversion ( 3.8 vs. 3.6 in men; $P<$ 0.001 ). Women reported slightly higher levels of social support (mean score: 17.5 vs. 17.3 in men, respectively, $p=0.38$ ), however, differences were not significant. Only $1.85 \%$ of respondents reported a low level of education. More women than men had a middle level of education ( 67.8 vs. $52.2 \%$ ), while men more often belonged to the highest education-category ( 40.4 vs. $30.7 \%$ in women; $P<0.001)$. No age differences were found in our sample.

Women had slightly more contact with physically aggressive or angry people and higher overall-values for interpersonal conflict. No gender differences were found with regard to frequency of conflictual contact. 
Table 1 Sample description (overall/by gender)

\begin{tabular}{|c|c|c|c|c|c|c|c|}
\hline \multirow[b]{2}{*}{ Variable } & \multicolumn{2}{|c|}{ Total $(n=2164)$} & \multicolumn{2}{|c|}{ Men $(n=856)$} & \multicolumn{2}{|c|}{ Women $(n=1308)$} & \multirow[t]{2}{*}{$P$-value ${ }^{*}$} \\
\hline & mean/\% & SD & mean/\% & SD & mean $/ \%$ & SD & \\
\hline Age & 49.3 & 7.9 & 49.4 & 8.1 & 49.3 & 7.7 & 0.924 \\
\hline Education low (\%) & 1.9 & & 2.3 & & 1.5 & & $P<0.001$ \\
\hline Education middle (\%) & 63.6 & & 57.2 & & 67.8 & & \\
\hline Education high (\%) & 34.5 & & 40.4 & & 30.7 & & \\
\hline Social resources & 17.5 & 5.0 & 17.3 & 5.1 & 17.5 & 4.9 & 0.385 \\
\hline Neuroticism & 3.2 & 1.1 & 3.0 & 1.1 & 3.4 & 1.2 & $P<0.001$ \\
\hline Extraversion & 3.7 & 1.3 & 3.6 & 1.2 & 3.8 & 1.3 & 0.004 \\
\hline Interpersonal conflict & 2.8 & 0.4 & 2.8 & 0.4 & 2.9 & 0.5 & $P<0.001$ \\
\hline Frequency. of conflictual contact & 3.3 & 0.5 & 3.3 & 0.4 & 3.3 & 0.5 & 0.197 \\
\hline Dealing with physically aggressive people & 1.8 & 0.5 & 1.7 & 0.5 & 1.8 & 0.5 & $P<0.001$ \\
\hline Dealing with angry people & 3.4 & 0.5 & 3.3 & 0.5 & 3.5 & 0.5 & $P<0.001$ \\
\hline Depressive symptoms (CES-D-score) & 10.0 & 6.9 & 8.6 & 5.4 & 10.8 & 7.6 & $P<0.001$ \\
\hline
\end{tabular}

$\mathrm{n}=2164$; age reported in years; education assessed according to CASMIN (Comparative Analysis of Social Mobility in Industrial Nations)-classification categories low, middle, and high; neuroticism and extraversion assessed by the NEO-16-AM; social resources assessed by the Lubben Social Network Scale; CES-D = Center for Epidemiological Studies Depression Scale; * $p$-values based on $\mathrm{Chi}^{2}$ - and two-sample t-tests, as appropriate

To illustrate different amounts of interpersonal conflict in specific occupations, examples of jobs with highest/lowest values in the respective types of contact are given in Table 2.

Interpersonal conflicts were especially common in occupations entailing care work, e.g. nurses/hospital staff, but also jobs in the education or service sector. Lowest values were found in various types of office/administrative jobs and engineering professions.

The results of an overall-multilevel linear regression model with gender as a covariate are presented in Table 3. The likelihood-ratio-test confirmed the superiority of the multilevel model over OLS-regression $(P<0.001)$. Only a small proportion of variance $(2.8 \%)$ in depressive symptomatology could be explained by differences between occupations, as indicated by the intraclass correlation coefficient (ICC, null model). This implies that variation in depressive symptomatology is for the most part due to differences between individuals, with a small level of variation explained by differences between occupations.

Women had higher levels of depressive symptoms than men ( $b=1.2$; 95\% CI: 0.66-1.74; Model 1). Depressive symptoms were reduced in people reporting higher levels of social resources $(b=-0.23$; $95 \%$ CI: -0.28 ; 0.18 ). Neuroticism was associated with increased depressive symptomatology, while higher levels of extraversion were linked to reduced depressive symptoms. No age differences were found. Education was linked to reduced risk of depressive symptoms, however, only for the highest level of educational attainment. Variation between jobs, indicated by the standard deviation of the random intercept, decreased from 1.14 to 0.51 , indicating little variation of depressive symptoms between jobs.

In Model 2, we investigated associations between occupational-level covariates and depressive symptoms. The amount of conflictual contact was not linked to depressive symptoms $(b=0.19 ; 95 \%-0.31 ; 0.68)$. The intercept was 7.45 (95\% CI: 4.86; 10.04). Associations with individual-level variables remained unchanged. Given the slightly smaller AIC-value, Model 1 should be considered the better-fitting model, i.e. the inclusion of interpersonal conflict does not improve the explanatory power of the model.

Tables 4 and Table 5 report the results of separate regression models for men and women. In the male subsample, $0.8 \%$ of variation in depressive symptoms could

Table 2 Examples of occupations with high/low values of interpersonal conflict

\begin{tabular}{lll}
\hline Job variable & Highest values & Lowest values \\
\hline Dealing with angry people & Policemen, educators, teachers, cashiers, nurses & $\begin{array}{l}\text { IT-engineers, research fellows, manufacturing, architects, } \\
\text { office/administrative staff, cosmeticians/hairdressers }\end{array}$ \\
$\begin{array}{ll}\text { Dealing with physically } \\
\text { aggressive people }\end{array}$ & $\begin{array}{l}\text { Policemen, tram/public transport drivers, (geriatric) } \\
\text { nurses, teachers }\end{array}$ & Engineers, IT-sector, carpenters, architects \\
Frequency of conflict situation & (Geriatric) nurses, educators, teachers, lawyers, & Lab assistants, kitchen aids, carpenters, office/administrative \\
& sales representatives & staff, commercial employees
\end{tabular}


Table 3 Results of multilevel linear regression to assess depressive symptomatology (CES-D), total sample $(n=2164)$

\begin{tabular}{|c|c|c|c|c|c|c|}
\hline \multirow[t]{2}{*}{ Variable } & \multicolumn{2}{|l|}{ Null model } & \multicolumn{2}{|l|}{ Model 1} & \multicolumn{2}{|l|}{ Model 2} \\
\hline & coeff. & $95 \% \mathrm{Cl}$ & coeff. & $95 \% \mathrm{Cl}$ & coeff. & $95 \% \mathrm{Cl}$ \\
\hline \multicolumn{7}{|l|}{$\underline{\text { Individual level }}$} \\
\hline Intercept/constant & 9.84 & $9.51 ; 10.14$ & 7.53 & $4.70 ; 10.35$ & 7.14 & $4.86 ; 10.04$ \\
\hline Female gender & & & 1.20 & $0.66 ; 1.74$ & 1.19 & $0.56 ; 1.46$ \\
\hline Age & & & 0.00 & $-0.04 ; 0.03$ & 0.00 & $-0.03 ; 0.02$ \\
\hline Education: middle & & & -1.84 & $-3.68 ; 0.01$ & -1.84 & $-3.21 ; 0.01$ \\
\hline Education: high (ref: low) & & & -2.61 & $-4.49 ;-0.72$ & -2.60 & $-4.04 ;-1.12$ \\
\hline Social resources & & & -0.23 & $-0.28 ;-0.18$ & -0.23 & $-0.28 ;-0.19$ \\
\hline Neuroticism & & & 2.55 & $2.33 ; 2.77$ & 2.55 & $2.29 ; 2.67$ \\
\hline Extraversion & & & -0.37 & $-0.56 ;-0.17$ & -0.37 & $-0.53 ;-0.20$ \\
\hline \multicolumn{7}{|l|}{ Occupational level } \\
\hline Interpersonal conflict & & & & & 0.14 & $-0.60 ; 0.83$ \\
\hline \multicolumn{7}{|l|}{ Random effects } \\
\hline Intercept SD & 1.14 & $0.57 ; 1.28$ & 0.51 & $0.24 ; 1.03$ & 0.50 & $0.18 ; 0.86$ \\
\hline ICC & 0.028 & & 0.008 & & 0.007 & \\
\hline Log Likelihood & -7233.77 & & -6888.12 & & -6888.041 & \\
\hline LR-Test & $C h i^{2}=23.30 ; P<0.001$ & & $C h i^{2}=4.42 ; P=0.018$ & & $C h i^{2}=4.23 ; P=0.020$ & \\
\hline AIC & $14,473.54$ & & $13,796.23$ & & $13,798.08$ & \\
\hline
\end{tabular}

Cl confidence interval; SD standard deviation; education assessed according to CASMIN (Comparative Analysis of Social Mobility in Industrial Nations)-classification categories low, middle, and high; neuroticism and extraversion assessed by the NEO-16-AM; social resources assessed by the Lubben Social Network Scale; CES-D Center for Epidemiological Studies Depression Scale; significant associations presented in bold type

Table 4 Results of multilevel linear regression to assess depressive symptomatology (CES-D) in men $(n=856)$

\begin{tabular}{|c|c|c|c|c|c|c|}
\hline \multirow[t]{2}{*}{ Variable } & \multicolumn{2}{|l|}{ Null model } & \multicolumn{2}{|l|}{ Model 1} & \multicolumn{2}{|l|}{ Model 2} \\
\hline & coeff & $95 \% \mathrm{Cl}$ & coeff & $95 \% \mathrm{Cl}$ & coeff & $95 \% \mathrm{Cl}$ \\
\hline \multicolumn{7}{|l|}{ Individual level } \\
\hline Intercept/constant & 8.65 & $8.26 ; 9.05$ & 7.91 & $4.52 ; 11.31$ & 8.30 & $4.20 ; 12.20$ \\
\hline Age & & & 0.03 & $-0.01 ; 0.07$ & 0.03 & $-0.01 ; 0.07$ \\
\hline Education: middle & & & -1.57 & $-3.71 ; 0.56$ & -1.60 & $-3.71 ; 0.56$ \\
\hline Education: high (ref: low) & & & -2.08 & $-4.25 ; 0.08$ & -2.09 & $-4.26 ; 0.07$ \\
\hline Social resources & & & -0.20 & $-0.26 ;-0.13$ & -0.20 & $-0.27 ;-0.13$ \\
\hline Neuroticism & & & 1.86 & $1.56 ; 2.17$ & 1.86 & $1.55 ; 2.16$ \\
\hline Extraversion & & & -0.26 & $-0.55 ; 0.02$ & -0.26 & $-0.54 ; 0.02$ \\
\hline \multicolumn{7}{|l|}{ Occupational level } \\
\hline Interpersonal conflict & & & & & -0.14 & $-0.98 ; 0.69$ \\
\hline \multicolumn{7}{|l|}{ Random effects } \\
\hline Intercept SD & 0.50 & $0.11 ; 2.23$ & $1.67^{*} 10^{-6}$ & $4.67^{*} 10^{-9} ; 0.00$ & $3.63 * 10^{-7}$ & $0.00 ; 0.00$ \\
\hline ICC & 0.008 & & $1.24^{*} 10^{-13}$ & & $5.81 * 10^{-15}$ & \\
\hline Log Likelihood & -2657.96 & & -2549.59 & & -2549.53 & \\
\hline LR-Test & $\mathrm{Chi}^{2}=0.55 ; P=0.229$ & & $C h i^{2}=0.00 ; P=1.00$ & & $\mathrm{Chi}^{2}=0.00 ; \mathrm{P}=1.00$ & \\
\hline AIC & 5321.93 & & 5117.17 & & 5119.06 & \\
\hline
\end{tabular}

Cl confidence interval; SD standard deviation; education assessed according to CASMIN (Comparative Analysis of Social Mobility in Industrial Nations)-classification categories low, middle, and high; neuroticism and extraversion assessed by the NEO-16-AM; social resources assessed by the Lubben Social Network Scale; CES-D Center for Epidemiological Studies Depression Scale; significant associations presented in bold type 
Table 5 Results of multilevel linear regression to assess depressive symptomatology (CES-D) in women $(n=1308)$

\begin{tabular}{|c|c|c|c|c|c|c|}
\hline \multirow[t]{2}{*}{ Variable } & \multicolumn{2}{|l|}{ Null model } & \multicolumn{2}{|l|}{ Model 1} & \multicolumn{2}{|l|}{ Model 2} \\
\hline & coeff. & $95 \% \mathrm{Cl}$ & coeff. & $95 \% \mathrm{Cl}$ & coeff. & $95 \% \mathrm{Cl}$ \\
\hline \multicolumn{7}{|l|}{ Individual level } \\
\hline Intercept/constant & 10.75 & $10.18 ; 11.33$ & 10.59 & $6.46 ; 14.72$ & 10.06 & $4.96 ; 15.16$ \\
\hline Age & & & -0.03 & $-0.07 ; 0.02$ & -0.03 & $-0.07 ; 0.02$ \\
\hline Education: middle & & & -2.23 & $-5.07 ; 0.62$ & -2.21 & $-5.06 ; 0.63$ \\
\hline Education: high (ref: low) & & & -3.34 & $-6.25 ;-0.43$ & -3.33 & $-6.24 ;-0.42$ \\
\hline Social resources & & & -0.27 & $-0.34 ;-0.19$ & -0.27 & $-0.34 ;-0.19$ \\
\hline Neuroticism & & & 2.93 & $2.63 ; 3.24$ & 2.94 & $2.63 ; 3.24$ \\
\hline Extraversion & & & -0.32 & $-0.59 ;-0.06$ & -0.32 & $-0.59 ;-0.06$ \\
\hline \multicolumn{7}{|l|}{ Occupational level } \\
\hline Interpersonal conflict & & & & & 0.17 & $-0.80 ; 1.14$ \\
\hline \multicolumn{7}{|l|}{ Random effects } \\
\hline Intercept SD & 1.05 & $0.53 ; 2.08$ & 0.65 & $0.28 ; 1.49$ & 0.63 & $0.27 ; 1.50$ \\
\hline ICC & 0.019 & & 0.010 & & 0.001 & \\
\hline Log Likelihood & -4500.89 & & -4280.40 & & -4280.34 & \\
\hline LR-Test & $\mathrm{Chi}^{2}=6.87 ; P=0.004$ & & $C h i^{2}=3.40 ; P=0.032$ & & $\mathrm{Chi}^{2}=3.05 ; P=0.040$ & \\
\hline AIC & 9007.77 & & 8578.80 & & 8580.68 & \\
\hline
\end{tabular}

Cl confidence interval; SD standard deviation; education assessed according to CASMIN (Comparative Analysis of Social Mobility in Industrial Nations)-classification categories low, middle, and high; neuroticism and extraversion assessed by the NEO-16-AM; social resources assessed by the Lubben Social Network Scale; CES-D Center for Epidemiological Studies Depression Scale; significant associations presented in bold type

be explained by differences between occupations (null model). Multilevel regression was not superior to OLS regression, as indicated by the likelihood ratio test $(p<$ 1.00). When entering individual-level factors (Model 1 ), social resources $(b=-0.2,95 \% \mathrm{CI}:-0.26 ;-0.13)$ and neuroticism $(b=1.86 ; 95 \%$ CI: $1.56 ; 2.16)$ were associated with depressive symptoms. Interpersonal conflict at work did not explain differences in depressive symptomatology (Model 2; $=-0.14 ; 95 \%$ CI: $-0.98 ; 0.69$ ).

Differences between occupations explained $1.9 \%$ of differences in depressive symptomatology in women (Table 5, null model). High levels of education and social resources were linked to lower levels of depressive symptoms (Model 1; b $=-3.34 ; 95 \% \mathrm{CI}-6.25 ;-0.34$ and -0.27 ; 95\% CI: $-0.34 ;-0.19$, respectively). Neuroticism was associated with more, extraversion with less depressive symptoms. When entering occupational-level covariates, the regression coefficients did not change, interpersonal conflict was not associated with depressive symptoms in women ( $b=0.17$; $95 \%$ CI: $-0.80 ; 1.14)$. However, the likelihood ratio test indicated the superiority of a multilevel approach over OLS regression for the female subsample. In both subsamples, adding information on interpersonal conflict did not improve the quality of the model, as indicated by the AIC favoring Model 1 both for men and women.

\section{Discussion}

Social conflict at work, as an objective job characteristic, was not associated with depressive symptomatology across 65 occupations in a large population-based sample. Differences in level of depressive symptoms were mainly explained by individual-level factors. The results do not confirm our hypothesis that social conflict at work is associated with higher levels of depressive symptoms. Some possible explanations for these findings are discussed below.

A possible interpretation is that job titles alone are too imprecise as indicators to be used in studies on occupational mental health: Jobs within the same occupation can vary largely between organizations, employers etc. regarding social relationships or the amount of conflict experienced [29, 65]. Regarding the small amount of variance due to occupational titles, more precise definitions of jobs or restriction to specific occupations might prove useful [38]. Conflicts at work were especially common among nurses, teachers or other professions in the service sector in our sample, corroborating existing evidence [23-26].

Since our analyses relied on cross-sectional data, we cannot rule out a possible selection bias/healthy-workereffect, i.e. people with impaired mental health are probably less likely to work in occupations characterized by high levels of conflict.

Another possible explanation for why we did not find an association between work-related conflict and depressive symptoms points towards the assessment of interpersonal conflict in our study: While the majority of studies on occupational mental health uses subjective 
measures to assess work-related relationships or stressors, we relied on an objective measure, using a database including detailed evaluations of various aspects of work. The objective assessment of interpersonal conflict, however, might have contributed to the nonsignificant association. It is possible that an association would have been detected if subjective measures of job features had been used. Subjective assessments include individual perceptions of stressors such as interpersonal conflict at work, which might mediate the influence of occupational stressors $[16,41]$. In other words: Objective job characteristics may be similar for all incumbents of an occupation, subjective perceptions and coping styles are not [66]. Expert ratings or average values of job characteristics for specific groups of workers might serve as more objective measures of workplace factors, but they might also capture less information about actual differences between individual working conditions [33]. This line of interpretation is supported by similar findings from the Whitehall II-study: Self-report measures of job strain were linked to depressive symptoms, whereas objective indices of job strain (i.e. expert ratings) were not [37]. A comprehensive review by van der Doef and Maes assessed studies testing the demand-control-(support) model and possible associations with mental health [67]. While overall there was much support for an association between job strain and impaired mental health when self-report measures were used, none of the studies in which job characteristics were assessed independently of the outcome measure supported a link with depressive symptoms. In a German study based on pension insurance data, conflicts in the workplace were found to be associated with higher likelihood of a depression diagnosis both in men and women [36]. However, this sample included only workers with a rehabilitation diagnosis, therefore excluding healthy cases and those with subclinical depressive symptoms. Comparisons between these findings and our study should be made with caution.

Individual-level covariates in our study mostly showed the expected association with depressive symptoms. Higher levels of neuroticism were associated with higher levels of depressive symptoms, higher levels of extraversion were linked to less depressive symptoms but only in women. Women reported more depressive symptoms than men, corroborating existing gender differences in the prevalence of depressive symptoms [68]. Men and women with higher levels of social resources reported less depressive symptoms. Social resources might be protective for mental health in general or ameliorate the impact of stressful events, e.g. from conflictual experiences in the workplace. This finding is in line with previous studies reporting a buffering effect of social resources on the impact of work-related stress $[69,70]$.
Higher levels of education were linked to less depressive symptoms, but only in women. Education can be understood as a form of personal capital or resource, enabling people to succeed e.g. in working contexts and to pursue personal goals [50]. Moreover, education can impact mental health indirectly since it generally enables access to higher-level jobs and higher income. This, however, was true only for the highest level of education and only for the female subsample, implying that education is protective against depressive symptomatology only beyond a certain threshold. Overall, our model was more appropriate for the female than for the male subsample, as indicated by likelihood ratio-tests and ICC. This might be due to less variation between occupations in the male subsample, leading to less explanatory power of the model.

\section{Strengths and limitations}

One strength of our study is the use of objective measures of job qualities as included in the O*NET, providing a valuable measure of occupational characteristics. Since the information on work characteristics in the $\mathrm{O}$ *NET are assessed by incumbents and job experts, respectively, it provides a valuable measure of interpersonal relationships in different occupations that is meaningful to interpret. Many studies in occupational health psychology share the common problem that specific instruments or questionnaires on job stressors are more adequate for certain occupations than for others [38], a risk that can - at least partially - be avoided when using information from the O*NET database. Comparable studies are rare in Germany and similar databases for the German workforce are not available so far. We used a large, population-based sample including a wide range of occupations, making the sample less selective than those in many previous studies. It has been pointed out that of the vast variety of occupations, only few have been studied in detail regarding their associations with mental health and depression [71].

We chose a multilevel framework for our research question based on theoretical grounds, since the qualities we wanted to investigate were assessed as features of jobs rather than of people. As a more technical indicator, the likelihood ratio test confirmed the nested structure of the data, indicating the superiority of a multilevel approach over OLS regression. A growing body of literature in the field of occupational mental health confirms this approach, reporting, on average, smaller associations than those found in OLS regressions and little variation between occupations [14, 29, 37, 40].

We restricted our analysis sample to people who experience at least a certain amount of interpersonal conflict at work by excluding the lowest quintile of values for the respective job characteristics. This might make 
our results more robust against statistical outliers and give a more accurate impression of the association between interpersonal conflict and depressive symptoms.

Certain limitations need to be addressed when interpreting our findings. First, since our study relies on cross-sectional data, no conclusions about causality can be drawn. Unfortunately, some potentially valuable information was not included in the LIFE-Adult baseline assessment, for example on the duration the subjects had been employed in the respective occupations. It might be possible that e.g. long periods of working in an occupation with high levels of interpersonal conflict may indeed raise the risk for depression. Then again, job experiences and histories of employment might provide useful resources and coping strategies which could possibly protect against work-related stressors. These questions, however, cannot be answered within the current study. Moreover, our data did not contain information on job involvement or employees' motivation as a potential moderating factor. However, comparable studies found little [72] or no support [73, 74] for job involvement having any influence on depressive symptoms or other mental health outcomes, therefore, the impact of this factor seems negligible.

Unfortunately, a substantial part of the original sample was lost due to missing values in the explanatory variables. However, a non-responder analysis revealed no differences in depressive symptomatology between responders and non-responders; therefore, this should not have influenced the results in a substantial way.

Lastly, a possible limitation arises from applying occupational information from a US-American database to a study sample from Germany. Since the O*NET data refer to the US-American labor market, slight differences regarding e.g. responsibilities, work context and social contacts made at work might occur between the same occupations in the US and Germany, respectively. However, since the O*NET data have previously been used in other health-related studies conducted in Germany [36, 75, 76], these possible differences should be negligible.

\section{Conclusions}

This study contributes to the literature on occupational factors and depressive symptoms using multilevel analyses. As in many comparable studies investigating the link between certain job aspects and mental health using individual- and job-level information, the association is not significant and job-level factors account for only litthe variance in depressive symptomatology. Our findings suggest that the association of interpersonal conflict at work and depressive symptoms does not differ between occupations. It can be assumed that approaches focusing only on the individual level of analysis via e.g. self-report measures tend to report more and stronger associations with depressive symptoms. A reason for this might be that it is less the objective job feature than rather people's individual perception of their job, i.e. cognitive and affective assessments of job characteristics, that are associated with depressive symptoms. If this was the case, strategies for prevention should especially focus on employees' perceptions of their jobs, promotion of psychosocial resources and individual assessments of oneself and the workplace. Against this background, further discussions on the possible factors of jobs that are associated with depressive symptoms should put a stronger focus on methodological questions and possible ways of conceptualizing research questions. This could help to disentangle the pathways through which individual and job-related factors impact workers' mental health.

The role of psychosocial aspects of employment and possible links to depression is still inconclusive. It can be argued that specific stressors in the workplace are more amendable to change than global frameworks like "work stress" or "job strain", therefore, further research addressing aspects like social relations in the workplace is highly warranted. Future investigations should be more precise about questions of operationalization and methodology: Does the study assess features of jobs or rather subjective perceptions of occupational environments, the latter reflecting both the stressor and its evaluation by the incumbent? Further research taking into account occupations and/or organizations which employees are nested in can shed more light on the factors that pose a danger to mental health.

\section{Abbreviations}

AIC: Akaike information criterion; CASMIN: Comparative Analysis of Social Mobility in Industrial Nations; CES-D: Center for Epidemiological Studies Depression Scale; Cl: Confidence interval; ICC: Intra-class correlation coefficient; LSNS: Lubben Social Network Scale; NEO-16 AM: NEO-16 Adjective Measure; O*NET: Occupational Information Network; OLS: Ordinary least squares; SD: Standard deviation

\section{Acknowledgements}

We thank all members of the LIFE study center for conducting the LIFEAdult-Study as well as all participants for their good collaboration. We acknowledge support from the German Research Foundation (DFG) and the University of Leipzig within the program of Open Access Publishing.

\section{Authors' contributions}

Andrea E. Zuelke conducted the statistical analyses, interpreted the data and drafted the manuscript. Susanne Roehr supported in interpreting the data and drafting the manuscript. Matthias L. Schroeter, A. Veronica Witte, Andreas Hinz, Christoph Engel and Cornelia Enzenbach revised the manuscript for intellectual content, read and approved the final version of the manuscript. Markus Loeffler, Joachim Thiery and Arno Villringer conceptualized and designed the study, revised the manuscript for intellectual content, read and approved the final version of the manuscript. Steffi G. Riedel-Heller conceptualized and designed the study, supervised the drafting of the manuscript, supported in interpreting the data, revised the manuscript for intellectual content, read and approved the final version of the manuscript. All authors read and approved the final manuscript. 


\section{Funding}

This publication is supported by LIFE - Leipzig Research Center for Civilization Diseases, University of Leipzig. LIFE is funded by means of the European Union, by the European Regional Development Fund (ERDF) and by means of the Free State of Saxony within the framework of the excellence initiative. This project was funded by means of the European Social Fund and the Free State of Saxony.

\section{Availability of data and materials}

The dataset analyzed during the current study is available from the corresponding author upon reasonable request.

\section{Ethics approval and consent to participate}

The LIFE-Adult Study was approved by the responsible ethics board of the Medical Faculty of the University of Leipzig. All participants provided written informed consent to participate prior to enrolment.

\section{Consent for publication}

Not applicable.

\section{Competing interests}

The authors declare that they have no competing interests.

\section{Author details}

${ }^{1}$ Institute of Social Medicine, Occupational Health and Public Health (ISAP), Medical Faculty, University of Leipzig, Philipp-Rosenthal-Str. 55, 04103 Leipzig, Germany. ${ }^{2}$ Max Planck Institute for Human Cognitive and Brain Sciences, Leipzig, Germany. ${ }^{3}$ University Hospital Leipzig, Day Clinic for Cognitive Neurology, Leipzig, Germany. ${ }^{4}$ Department of Medical Psychology and Medical Sociology, University of Leipzig, Leipzig, Germany. ${ }^{5}$ Institute for Medical Informatics, Statistics and Epidemiology (IMISE), University of Leipzig, Leipzig, Germany. ${ }^{6}$ Institute of Laboratory Medicine, Clinical Chemistry and Molecular Diagnostics (ILM), University Hospital Leipzig, Leipzig, Germany.

\section{Received: 13 September 2019 Accepted: 4 February 2020}

Published online: 12 February 2020

\section{References}

1. Kirsten W. Making the link between health and productivity at the workplace-a global perspective. Ind Health. 2010;48:251-5.

2. Bonde JPE. Psychosocial factors at work and risk of depression: a systematic review of the epidemiological evidence. Occup Environ Med. 2008;65:438-45. https://doi.org/10.1136/oem.2007.038430.

3. Goetzel RZ, Long SR, Ozminkowski RJ, Hawkins K, Wang S, Lynch W. Health, absence, disability, and Presenteeism cost estimates of certain physical and mental health conditions affecting U.S. employers. J Occup Environ Med. 2004;46:398-412. https://doi.org/10.1097/01.jom.0000121151.40413.bd.

4. Eurostat. Duration of working life - statistics. 2019. https://ec.europa.eu/ eurostat/statistics-explained/index.php/Duration_of_working_life_-_ statistics\#Increase_in_expected_duration_of_working_life_in_the_EU. Accessed 16 Dec 2019

5. Steyn R, Vawda N. Job characteristics: their relationship to job satisfaction, stress and depression. J Psychol Afr. 2014;24:281-4. https://doi.org/10.1080/ 14330237.2014.906076.

6. Theorell T, Hammarström A, Aronsson G, Bendz LT, Grape T, Hogstedt C, et al. A systematic review including meta-analysis of work environment and depressive symptoms. BMC Public Health. 2015;15:738.

7. Madsen IEH, Nyberg ST, Magnusson Hanson LL, Ferrie JE, Ahola K, Alfredsson $L$, et al. Job strain as a risk factor for clinical depression: systematic review and meta-analysis with additional individual participant data. Psychol Med. 2017;47:1342-56. https://doi.org/10.1017/ S003329171600355X

8. Karasek RA Jr. Job demands, job decision latitude, and mental strain: Implications for job redesign. Adm Sci Q. 1979;24:285-308.

9. Johnson JV, Hall EM. Job strain, work place social support, and cardiovascular disease: a cross-sectional study of a random sample of the Swedish working population. Am J Public Health. 1988;78:1336-42.

10. Johnson JV, Hall EM, Theorell T. Combined effects of job strain and social isolation on cardiovascular disease morbidity and mortality in a random sample of the Swedish male working population. Scand J Work Environ Health. 1989;15:271-9. https://doi.org/10.5271/sjweh.1852.
11. Netterstrøm B, Conrad N, Bech P, Fink P, Olsen O, Rugulies R, Stansfeld S. The relation between work-related psychosocial factors and the development of depression. Epidemiol Rev. 2008;30:118-32.

12. Bakker $A B$, Demerouti $E$. The job demands-resources model: state of the art. J Managerial Psych. 2007;22:309-28. https://doi.org/10.1108/02683940710733115.

13. Marchand A, Durand P. Psychological distress, depression, and burnout: similar contribution of the job demand-control and job demand-controlsupport models? J Occup Environ Med. 2011;53:185-9. https://doi.org/10. 1097/JOM.0b013e318206f0e9.

14. Marchand A, Demers A, Durand P. Does work really cause distress? The contribution of occupational structure and work organization to the experience of psychological distress. Soc Sci Med. 2005;61:1-14. https://doi.org/10.1016/j.socscimed.2004.11.037.

15. Hobfoll SE, Geller P, Dunahoo C. Women's coping: communal versus individualistic orientation. In: The handbook of work and health psychology, vol. 237; 2003

16. Spector PE, Jex SM. Development of four self-report measures of job stressors and strain: interpersonal conflict at work scale, organizational constraints scale, quantitative workload inventory, and physical symptoms inventory. J Occup Health Psychol. 1998;3:356.

17. Narayanan L, Menon S, Spector PE. Stress in the workplace: a comparison of gender and occupations. J Organizational Behavior: Int J Industrial, Occupational Organizational Psychology Behavior. 1999;20:63-73.

18. Burton J, World Health Organization. WHO healthy workplace framework and model: background and supporting literature and practices. 2010

19. Ilies R, Johnson MD, Judge TA, Keeney J. A within-individual study of interpersonal conflict as a work stressor: dispositional and situational moderators. J Organiz Behav. 2011;32:44-64. https://doi.org/10.1002/job.677.

20. Fox S, Spector PE, Miles D. Counterproductive work behavior (CWB) in response to job stressors and organizational justice: some mediator and moderator tests for autonomy and emotions. J Vocat Behav. 2001;59:291309. https://doi.org/10.1006/jvbe.2001.1803.

21. Penney LM, Spector PE. Job stress, incivility, and counterproductive work behavior (CWB): the moderating role of negative affectivity. J Organizational Behavior: Int J Industrial, Occupational Organizational Psychology Behavior. 2005;26:777-96.

22. Kern JH, Grandey AA. Customer incivility as a social stressor: the role of race and racial identity for service employees. J Occup Health Psychol. 2009;14: 46-57. https://doi.org/10.1037/a0012684.

23. McKenna BG, Smith NA, Poole SJ, Coverdale JH. Horizontal violence: experiences of registered nurses in their first year of practice. J Adv Nurs. 2003;42:90-6.

24. Farrell GA, Bobrowski C, Bobrowski P. Scoping workplace aggression in nursing: findings from an Australian study. J Adv Nurs. 2006;55:778-87. https://doi.org/10.1111/j.1365-2648.2006.03956.x.

25. Powell JE, Powell AL, Petrosko JM. School climate as a predictor of incivility and bullying among public school employees: a multilevel analysis. J Sch Violence. 2015;14:217-44. https://doi.org/10.1080/15388220.2014.906917.

26. Reio TG, Reio SM. Workplace incivility in schools. Int J Adult Vocational Education Technol. 2011;2:23-35. https://doi.org/10.4018/javet.2011010103.

27. Keenan A, Newton TJ. Stressful events, stressors and psychological strains in young professional engineers. J Organ Behav. 1985;6:151-6.

28. Narayanan L, Menon S, Spector P. A cross-cultural comparison of job stressors and reactions among employees holding comparable jobs in two countries. Int J Stress Manag. 1999;6:197-212.

29. Morrison D, Payne RL, Wall TD. Is job a viable unit of analysis?: a multilevel analysis of demand-control-support models. J Occup Health Psychol. 2003:8: 209-19. https://doi.org/10.1037/1076-8998.8.3.209.

30. Alterman T, Grosch J, Chen X, Chrislip D, Petersen M, Krieg E, et al. Examining associations between job characteristics and health: linking data from the occupational information network (O*NET) to two U.S. national health surveys. J Occup Environ Med. 2008;50:1401-13. https://doi.org/10. 1097/JOM.0b013e318188e882.

31. Guglielmi D, Simbula S, Vignoli M, Bruni I, Depolo M, Bonfiglioli R, et al. Solving a methodological challenge in work stress evaluation with the stress assessment and research toolkit (StART): a study protocol. J Occupational Medicine Toxicology. 2013;8:18.

32. Tennant C. Work-related stress and depressive disorders. J Psychosom Res. 2001;51:697-704.

33. Theorell T, Hasselhorn HM. On cross-sectional questionnaire studies of relationships between psychosocial conditions at work and health--are they 
reliable? Int Arch Occup Environ Health. 2005;78:517-22. https://doi.org/10 1007/s00420-005-0618-6.

34. Heinisch DA, Jex SM. Negative affectivity and gender as moderators of the relationship between work-related stressors and depressed mood at work. Work stress. 1997;11:46-57.

35. Zimmerman FJ, Christakis DA, Vander SA. Tinker, tailor, soldier, patient: work attributes and depression disparities among young adults. Soc Sci Med. 2004;58:1889-901. https://doi.org/10.1016/S0277-9536(03)00410-6.

36. Fischer S, Wiemer A, Diedrich L, Moock J, Rössler W. Hell is other people? Gender and interactions with strangers in the workplace influence a person's risk of depression. PLoS ONE. 2014;9:e103501. https://doi.org/10. 1371/journal.pone.0103501.

37. Stansfeld SA, North FM, White I, Marmot MG. Work characteristics and psychiatric disorder in civil servants in London. J Epidemiol Community Health. 1995:49:48-53.

38. Kasl SV. Measuring job stressors and studying the health impact of the work environment: an epidemiolgic commentary. J Occup Health Psychol. 1998;3: 390-401. https://doi.org/10.1037/1076-8998.3.4.390.

39. Benavides FG, Benach J, Muntaner C. Psychosocial risk factors at the workplace: is there enough evidence to establish reference values? J Epidemiol Community Health. 2002;56:244-5. https://doi.org/10.1136/jech.56.4.244.

40. Elovainio M, Kivimäki M, Steen N, Kalliomäki-Levanto T. Organizational and individual factors affecting mental health and job satisfaction: a multilevel analysis of job control and personality. J Occup Health Psychol. 2000;5:269-77. https:/doi.org/10.1037//1076-8998.5.2.269.

41. Martin A, Karanika-Murray M, Biron C, Sanderson K. The psychosocial work environment, employee mental health and organizational interventions: improving research and practice by taking a multilevel approach. Stress Health. 2016;32:201-15. https://doi.org/10.1002/smi.2593.

42. Marklund S, Bolin M, von Essen J. Can individual health differences be explained by workplace characteristics?--a multilevel analysis. Soc Sci Med. 2008;66:650-62. https://doi.org/10.1016/.socscimed.2007.09.008.

43. Jylhä P, Isometsä E. The relationship of neuroticism and extraversion to symptoms of anxiety and depression in the general population. Depress Anxiety. 2006;23:281-9. https://doi.org/10.1002/da.20167.

44. Bienvenu OJ, Samuels JF, Costa PT, Reti IM, Eaton WW, Nestadt G. Anxiety and depressive disorders and the five-factor model of personality: a higherand lower-order personality trait investigation in a community sample. Depress Anxiety. 2004;20:92-7. https://doi.org/10.1002/da.20026.

45. Cox BJ, McWilliams LA, Enns MW, Clara IP. Broad and specific personality dimensions associated with major depression in a nationally representative sample. Compr Psychiatry. 2004;45:246-53. https://doi.org/10.1016/j. compsych.2004.03.002.

46. Brezo J, Paris J, Turecki G. Personality traits as correlates of suicidal ideation, suicide attempts, and suicide completions: a systematic review. Acta Psychiat Scand. 2006;113:180-206. https://doi.org/10.1111/j.1600-0447.2005.00702.x.

47. Kendler KS, Kuhn J, Prescott CA. The interrelationship of neuroticism, sex, and stressful life events in the prediction of episodes of major depression. Am J Psychiatry. 2004;161:631-6. https://doi.org/10.1176/appi.ajp.161.4.631

48. Gariépy G, Honkaniemi H, Quesnel-Vallée A. Social support and protection from depression: systematic review of current findings in Western countries. Br J Psychiatry. 2016;209:284-93. https://doi.org/10.1192/bjp.bp.115.169094.

49. Lorant V, Deliège $D$, Eaton W, Robert A, Philippot P, Ansseau M. Socioeconomic inequalities in depression: a meta-analysis. Am J Epidemiol. 2003:157:98-112.

50. Bjelland I, Krokstad S, Mykletun A, Dahl AA, Tell GS, Tambs K. Does a higher educational level protect against anxiety and depression? The HUNT study. Soc Sci Med. 2008;66:1334-45. https://doi.org/10.1016/j.socscimed.2007.12.019.

51. Vermeulen M, Mustard C. Gender differences in job strain, social support at work, and psychological distress. J Occup Health Psychol. 2000;5:428-40. https://doi.org/10.1037/1076-8998.5.4.428.

52. Shigemi J, Mino Y, Ohtsu T, Tsuda T. Effects of perceived job stress on mental health. A longitudinal survey in a Japanese electronics company. Eur J Epidemiol. 2000;16:371-6.

53. Appelberg K, Romanov K, Heikkilä K, Honkasalo M-L, Koskenvuo M. Interpersonal conflict as a predictor of work disability: a follow-up study of 15,348 finnish employees. J Psychosom Res. 1996;40:157-67. https://doi.org/ 10.1016/0022-3999(95)00576-5.

54. Salin D. Workplace bullying among business professionals: prevalence, Gender Differences Role Organizational Politics pistes 2005. doi:https://doi. org/10.4000/pistes.3159.
55. Blumenthal JA. The reasonable woman standard: a meta-analytic review of gender differences in perceptions of sexual harassment. Law Hum Behav. 1998;22:33-57.

56. Gross JJ, John OP. Individual differences in two emotion regulation processes: implications for affect, relationships, and well-being. J Pers Soc Psychol. 2003;85:348.

57. Loeffler M, Engel C, Ahnert P, Alfermann D, Arelin K, Baber R, et al. The LIFEadult-study: objectives and design of a population-based cohort study with 10,000 deeply phenotyped adults in Germany. BMC Public Health. 2015;15: 691. https://doi.org/10.1186/s12889-015-1983-z.

58. Radloff LS. The CES-D scale: a self-report depression scale for research in the general population. Appl Psychol Meas. 1977;1:385-401.

59. Hautzinger M, Bailer M, Hofmeister D, Keller F. ADS (2012)-Allgemeine Depressionsskala (2012). Hogrefe, Göttingen Google Scholar: Tests Info; 2012.

60. Lubben J, Blozik E, Gillmann G, lliffe S, von Renteln Kruse W, Beck JC, Stuck AE. Performance of an abbreviated version of the Lubben social network scale among three European community-dwelling older adult populations. The Gerontologist. 2006;46:503-13.

61. Herzberg PY, Brähler E. Assessing the big-five personality domains via short forms. Eur J Psychol Assess. 2006;22:139-48. https://doi.org/10.1027/10155759.22.3.139.

62. Brauns $\mathrm{H}$, Scherer $\mathrm{S}$, Steinmann S. The CASMIN educational classification in international comparative research. In: Advances in cross-national comparison: Springer; 2003. p. 221-44.

63. National Research Council. A Database for a Changing Economy: Review of the Occupational Information Network (O*NET). Washington, DC: The National Academies Press; 2010.

64. Meyer JD, Cifuentes M, Warren N. Association of self-rated physical health

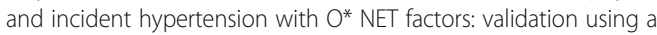
representative national survey. J Occup Environ Med. 2011;53:139-45.

65. Ford MT. Job-occupation misfit as an occupational stressor. J Vocat Behav. 2012;80:412-21. https://doi.org/10.1016/j.jvb.2011.10.004.

66. Stuke $H$, Bermpohl F. Welche Arbeitsbedingungen begünstigen die Entwicklung einer depressiven Störung? Psychiatr Prax. 2016;43:245-52.

67. van der Doef M, Maes S. The job demand-control (-support) model and psychological well-being: a review of 20 years of empirical research. Work stress. 1999;13:87-114.

68. Thom J, Hoebel J, Nübel J, Kurth T, Hapke U. Nehmen Depressionsdiagnosen bevölkerungsweit zu? Psychiatr Prax. 2019. https://doi.org/10.1055/a-0895-7550

69. LaRocco JM, House JS, French JRP Jr. Social support, occupational stress, and health. J Health Soc Behav. 1980:202-18.

70. Lim VKG. Job insecurity and its outcomes: moderating effects of work-based and nonwork-based social support. Hum Relat. 1996;49:171-94.

71. Muchinsky PM, Raines JM. The overgeneralized validity of validity generalization. J Organ Behav. 2013;34:1057-60.

72. Firth H, Britton P. 'Burnout', absence and turnover amongst British nursing staff. J Occup Psychol. 1989;62:55-9.

73. Frone MR, Russell M, Cooper ML. Job stressors, job involvement and employee health: a test of identity theory. J Occup Organ Psychol. 1995;68:1-11.

74. Burke RJ. Workaholism in organizations: psychological and physical wellbeing consequences. Stress Medicine. 2000;16:11-6.

75. Hussenoeder FS, Conrad I, Roehr S, Glaesmer H, Hinz A, Enzenbach C, et al. The association between mental demands at the workplace and cognitive functioning: the role of the big five personality traits. Aging Ment Health. 2019:1-7. https://doi.org/10.1080/13607863.2019.1617244.

76. Then FS, Luck T, Luppa M, Arélin K, Schroeter ML, Engel C, et al. Association between mental demands at work and cognitive functioning in the general population-results of the health study of the Leipzig research center for civilization diseases (LIFE). J Occupational Medicine Toxicology. 2014;9:23.

\section{Publisher's Note}

Springer Nature remains neutral with regard to jurisdictional claims in published maps and institutional affiliations. 